\title{
AMORPHOUS CARBON-SILICON ALLOYS PREPARED BY A HIGH PLASMA DENSITY SOURCE
}

\author{
A. C. FERRARI ${ }^{a}$, B. RACINE ${ }^{a, b}$, N. A. MORRISON ${ }^{a}$, I. HUTCHINGS ${ }^{c}$, W. I. \\ MILNE $^{\mathrm{a}}, \mathrm{J}$. ROBERTSON ${ }^{\mathrm{a}}$ \\ ${ }^{a}$ Engineering Department, Cambridge University, Cambridge CB2 1PZ, UK \\ ${ }^{b}$ Laboratoire de Physique de la Matierie Condensee, Amiens, France \\ ${ }^{c}$ Materials Science and Metallurgy Department, Cambridge University, UK
}

\begin{abstract}
The addition of silicon to hydrogenated amorphous carbon can have the advantageous effect of lowering the compressive stress, improving the thermal stability of its hydrogen and maintaining a low friction coefficient up to high humidity. Most experiments to date have been on a- $\mathrm{C}_{1-x} \mathrm{Si}_{\mathrm{x}}: \mathrm{H}$ alloys deposited by $\mathrm{RF}$ plasma enhanced chemical vapour deposition (PECVD). This method gives alloys with considerable hydrogen content and only moderate hardness. Here, we use a high plasma density source, the electron cyclotron wave resonance (ECWR) source, to prepare films with a high deposition rate. The composition and bonding in the alloys is determined by XPS, visible and UV Raman and FTIR spectroscopy. We find that it is possible to produce hard, low stress, low friction, almost humidity insensitive a- $C_{1}$. ${ }_{x} \mathrm{Si}_{\mathrm{x}}: \mathrm{H}$ alloys with a good optical transparency and a band gap over $2 \mathrm{eV}$.
\end{abstract}

\section{INTRODUCTION}

Amorphous $\mathrm{C}-\mathrm{Si}\left(\mathrm{a}-\mathrm{C}_{1-\mathrm{x}} \mathrm{Si}_{\mathrm{x}}\right)$ and hydrogenated amorphous $\mathrm{C}-\mathrm{Si}\left(\mathrm{a}-\mathrm{C}_{1-\mathrm{x}} \mathrm{Si}_{\mathrm{x}}: \mathrm{H}\right)$ alloys are of both fundamental and technological interest. The fundamental interest arises from the possibility of studying the preference for chemical ordering or heteroatom bonding in a tetrahedrally coordinated $\mathrm{sp}^{3}$ bonded alloy system around $\mathrm{x}=0.5$, where the crystalline compounds exists. The technological interest arises from the possibility of obtaining low stress, low friction, humidity insensitive coatings [13]. Moreover band calculations suggest that the band gap of $\mathrm{C}$-rich alloys depends on the $\mathrm{C}-\mathrm{C}$ bonding, not the $\mathrm{C}-\mathrm{Si}$ bonding, so that band gap need not be reduced by the addition of silicon [1]. It should thus be possible to produce hard, low stress, low friction, almost moisture insensitive $\mathrm{a}-\mathrm{C}_{1-\mathrm{x}} \mathrm{Si}_{\mathrm{x}}: \mathrm{H}$ alloys with a good optical transparency and a band gap over $2 \mathrm{eV}$.

Most of the studies conducted so far considered the introduction of $\mathrm{Si}$ into hydrogenated amorphous carbon $(\mathrm{a}-\mathrm{C}: \mathrm{H})$ produced by PECVD or Electron Cyclotron Resonance, see ref. [4] for a review. Hydrogenated tetrahedral amorphous carbon (ta$\mathrm{C}: \mathrm{H})$ can be deposited using a Plasma Beam Source [5] or an Electron Cyclotron Wave Resonance Source [6]. In a-C: $\mathrm{H}$ a high $\mathrm{sp}^{3}$ content is obtained mainly by saturating $\mathrm{C}=\mathrm{C}$ bonds as $\mathrm{CH}_{\mathrm{x}}$ groups rather than by increasing the fraction of $\mathrm{C}-\mathrm{C}$ bonds. Ta-C:H differs in that a higher $\mathrm{sp}^{3}$ content occurs at a fixed lower $\mathrm{H}$ content of $25-30 \%$. This results in ta-C:H having a higher density (up to $2.4 \mathrm{~g} / \mathrm{cm}^{3}$ [7]), Young's modulus ( 300GPa [8]) and hardness [5] and a lower $\mathrm{H}$ content, compared to a-C:H with similar $\mathrm{sp}^{3}$ content. On the other hand, the higher ion energy and ionisation obtained in the ECWR source, with respect to PECVD, results in much higher stresses of $\sim 6-7 \mathrm{GPa}$ [6], similar to as-deposited ta-C, limiting the maximum achievable 
thickness to $\sim 100 \mathrm{~nm}$. This contrasts with as-deposited diamond like a-C:H which has $\sim 1-2 \mathrm{GPa}$ of stress.

The friction coefficient, $\mu$, of a-C:H is very low $(0.03-0.05)$ in inert atmosphere in low humidity conditions, but rises to $\sim 0.5$ at high humidity [9], whilst diamond is humidity insensitive. On the other hand laser-deposited ta-C has a higher value of $\sim 0.2$ at low humidity, decreasing slowly with increasing humidity [10]. Gangopadhyay et al.[11] and Oguri et al.[2,3] have shown that $\mathrm{Si}$ introduction in a$\mathrm{C}: \mathrm{H}$ could reduce $50 \%-80 \%$ the stress and result in friction coefficients lower than 0.1 up to $80 \%$ humidity. However, for a fixed bias voltage, only a $\sim 37 \%$ stress reduction was achieved [11]. In this paper the effect of Si introduction on the structure and properties of ta-C: $\mathrm{H}$ is presented.

\section{EXPERIMENT}

\section{Deposition}

Films were deposited using an ECWR source (Fig 1) at room temperature from a $\mathrm{SiH}_{4} / \mathrm{C}_{2} \mathrm{H}_{2}$ mixture, with gas ratio $\mathrm{R}=\mathrm{SiH}_{4}(\mathrm{sccm}) /\left[\mathrm{C}_{2} \mathrm{H}_{2}(\mathrm{sccm})+\mathrm{SiH}_{4}(\mathrm{sccm})\right]$ varying from 0 to $100 \%$, to produce all a- $\mathrm{C}_{\mathrm{x}}: \mathrm{Si}_{1-\mathrm{x}}: \mathrm{H}$ alloys from ta-C:H to a-Si:H. The ECWR, or WAve Resonance Plasma source (WARP), is a $13.6 \mathrm{MHz}$ single turn inductively coupled source. A grounded extraction electrode completes the assembly (Fig 1). The transverse magnetic field generated via the Helmholtz coils splits the electromagnetic waves in two circularly polarised waves. The right hand polarised wave is no longer reflected by the plasma, but is strongly coupled to the bulk plasma, so allowing efficient power transfer from the RF to the plasma, and enabling the formation of a high plasma density up to two orders of magnitude higher than in a capacitive source. The wave resonance condition is achieved when a stanting wave is set up within the source cross section [6]. In each case the deposition conditions were fixed, with the exception of $\mathrm{R}$. The operating pressure was $\sim 1.2 \times 10^{-3} \mathrm{mbar}$, maintained by a turbomolecular pump, with a pumping speed of $1600 \mathrm{l} / \mathrm{s}$. The RF power was $285 \mathrm{~W}$, the voltage and current across the Helmholtz coils were $\sim 4.71 \mathrm{~V}$ and $\sim 980 \mathrm{~mA}$, respectively, resulting in an ion energy of $\sim 150 \mathrm{eV}$ for a $100 \% \mathrm{C}_{2} \mathrm{H}_{2}$ plasma [6].

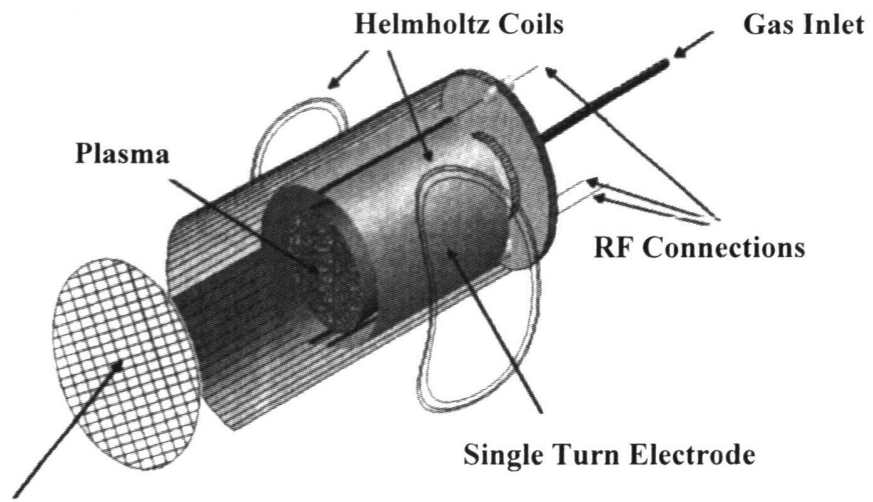

\section{Grounded Extraction Grid}

Fig 1. Schematic diagram of the ECWR source 


\section{Characterisation}

Films were deposited on $\mathrm{Si}$ and quartz for structural, mechanical and optical characterisation. Film thickness and refractive index at $633 \mathrm{~nm}$ were determined by Ellipsometry (Gaertner Scientific L117). Film stress was determined using Stoney's equation. The surface curvature of the Si substrate, before and after deposition, was measured by a Sloan DektakIla profilometer. The optical gap ( $\mathrm{E}_{04}$ and Tauc) and complex refractive index were measured with an Ati-UNICAM UV-visible spectrometer. Visible Raman spectra (at $514.5 \mathrm{~nm}$ ) were collected in a Renishaw micro-Raman 2000 spectrometer. UV-Raman spectra (at $244 \mathrm{~nm}$ ) were collected on a UV-enhanced CCD camera on a Renishaw micro-Raman system 1000, modified for use at $244 \mathrm{~nm}$, with fused silica optics throughput. Fourier Transform Infra-Red spectrometry (FTIR) was performed on a ATI-Mattenson RS1 system. The C/Si ratio in the films was investigated by X-Ray Photoelectron Spectroscopy. The percentage of $\mathrm{sp}^{3}$ bonded carbon content was derived analysing the carbon $\mathrm{K}$ edge in the High loss Electron Energy Loss Spectra (EELS). EELS measurements were carried out on a dedicated VG501 scanning transmission electron microscope fitted with a spectrometer with a McMullan parallel EELS detection system [7]. Friction measurements were performed on a ball-on-disk tribometer. Stainless steel balls (AISI $52100,6.35 \mathrm{~mm}$ diameter) were used during tests, which were conducted both in air and under a controlled humidity environment (10,50 and $80 \%$ relative humidity). A load of $2 \mathrm{~N}$ was applied, corresponding to a Hertzian contact pressure of $370 \mathrm{MPa}$. A sliding speed of $0.3 \mathrm{~m} / \mathrm{s}$ was used in each of the measurements. A second series of friction measurements were performed with DLC-coated steel balls. An a-C:H layer was deposited with a PECVD system, at $200 \mathrm{~W}$ and $100 \mathrm{mTorr}$ pressure. In this conditions a typical diamond-like a-C:H is obtained on $\mathrm{Si}$, with a Tauc gap of $\sim 1.5 \mathrm{eV}$.

\section{RESULTS}

The deposition rate was $7.5-5 \AA / s$, slightly decreasing with increasing relative silane flow rate $\mathrm{R}$. This is comparable with the deposition rate reported by Oguri et al. [2,3] and Gangopadhyay et al.[11], but 5 to 10 times higher than ECR deposited films [12]. Fig 2 shows the stress as a function of R. A stress reduction of $\sim 45 \%$ is observed for $\mathrm{R}=10 \%$, similar to what reported by Gangopadhyay [11] for films grown at a fixed bias voltage. Almost full stress release happens only for $\mathrm{R}>60 \%$. However films thicker than $500 \mathrm{~nm}$ could be grown at $\mathrm{R}=20 \%$. The refractive index at $633 \AA$ remains $\sim 2.2$ until $\mathrm{R} \sim 60 \%$, then

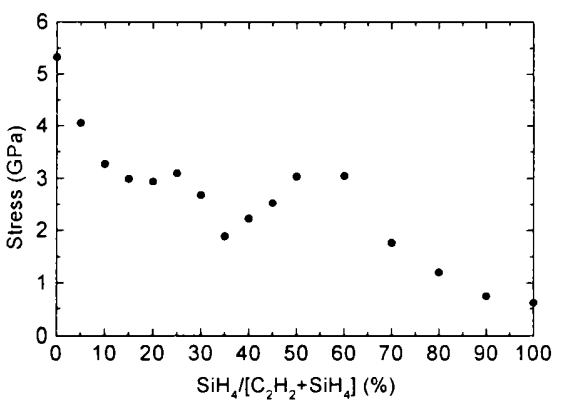

Fig 2: Stress vs. R increases towards $\sim 3.2$, typical of a$\mathrm{Si}: \mathrm{H}$. Fig 3 displays the optical gap ( $E_{04}$ and $E_{T a u c}$ ) as a function of R. $E_{04}$ starts at $\sim 2.1 \mathrm{eV}$, typical of ta-C:H. increasing to a maximum of $\sim 3.2 \mathrm{eV}$ for $\mathrm{R}=70 / 80 \%$, before decreasing towards values typical for a-Si:H. This suggest that $\mathrm{R}=70 / 80 \%$ corresponds to $\mathrm{C} / \mathrm{Si} \sim 40-50 \%$ within the films thus indicating a lower $\mathrm{Si}$ incorporation than $\mathrm{R}$. This is consistent with XPS data, Fig $4(\mathrm{Si} /[\mathrm{C}+\mathrm{Si}]=42 \%$ at $\mathrm{R}=80 \%)$. 


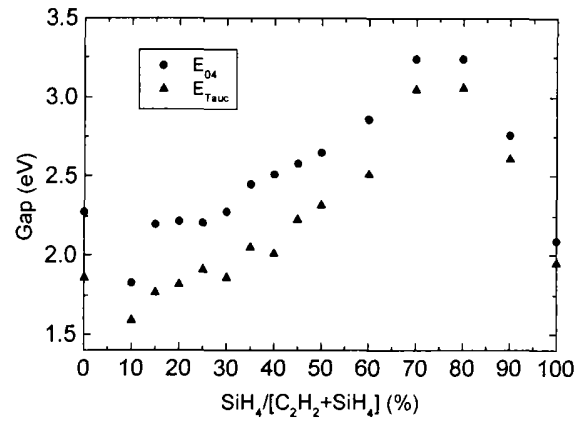

Fig 3: Optical gap vs. gas flow ratio $\mathrm{R}$

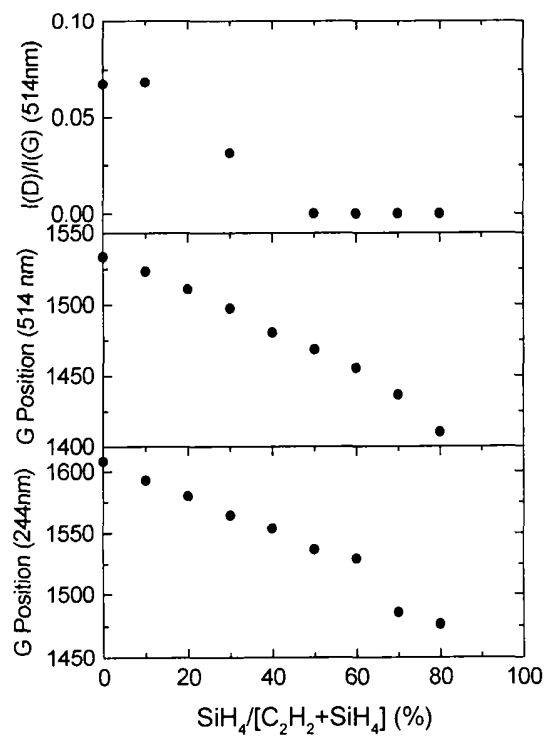

Fig. 5 Variation of $\mathrm{I}(\mathrm{D}) / \mathrm{I}(\mathrm{G})$ and $\mathrm{G}$ position in $514 \mathrm{~nm}$ Raman and $\mathrm{G}$ position in UV Raman vs. $R$

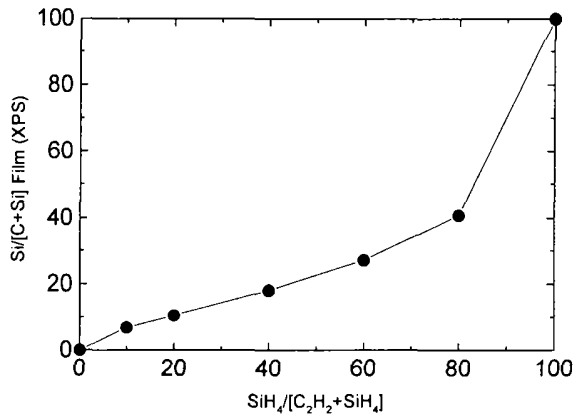

Fig 4: $\mathrm{Si} /[\mathrm{C}+\mathrm{Si}]$ ratio in the films vs. $\mathrm{R}$

Fig 5 shows $\mathrm{G}$ peak position and the ratio of intensities of $D$ peak and $G$ peak, I(D)/I(G), for 514nm Raman and G peak position for UV Raman. The G peak is due to the relative motion of $\mathrm{sp}^{2}$ carbon atoms, whilst the $\mathrm{D}$ peak is due to breathing modes of aromatic clusters [13]. The as-deposited ta-C:H still shows a very small $\mathrm{D}$ peak, but increasing $\mathrm{Si}$ content opens up the remaining rings, resulting in a olefinic $\mathrm{sp}^{2}$ structure and a higher optical gap [1]. This is reflected in the decrease of the ratio $\mathrm{I}(\mathrm{D}) / \mathrm{I}(\mathrm{G})$. The decrease in $\mathrm{G}$ peak position both in visible and in UV Raman is explained by the softening of the $\mathrm{C}=\mathrm{C}$ modes induced by the increasing number of softer $\mathrm{C}$-Si bonds, due to the heavier Si mass. The absence of any $\mathrm{C} \mathrm{sp}{ }^{2}$ ring clustering is further shown by the parallel behaviour of the G peak in UV Raman and Visible Raman, the latter being just downshifted by $\sim 72 \mathrm{~cm}^{-1}$ with respect to UV. This means that there is an

unique $\mathrm{C} \mathrm{sp}^{2}$ configuration corresponding to a given Si content, thus allowing a direct quantification of the Si/C ratio from Raman parameters (cfr. Fig 4/5) [14]. Thus we can assert that the fraction of $\mathrm{C}-\mathrm{C} \mathrm{sp}{ }^{3}$ does not decrease with $\mathrm{Si}$ addition [13]. This is confirmed by EELS measurements, that give an almost constant $\mathrm{sp}^{3}$ fraction $\sim 70 \%$ up to $\mathrm{R}=40 \%$. The evolution of the bonding structure has been also investigated by FTIR, shown in Fig 6,7 for $\mathrm{R}=0,20,40,60,80,100 \%$. Fig 6 shows the increasing contribution of the C-Si stretching band at $\sim 770 \mathrm{~cm}^{-1}$ [12], with increasing $\mathrm{R}$. It reaches a maximum for $\mathrm{R}=80 \%$, then being replaced by the $\mathrm{Si}-\mathrm{H}_{\mathrm{n}}$ modes of a-Si:H $(\mathrm{R}=100 \%)$ [12]. Fig 7 shows an increase of the $\mathrm{Si}-\mathrm{H}_{2}$ stretching modes at $\sim 2100 \mathrm{~cm}^{-1}$ relative to the $\mathrm{C}-\mathrm{H}_{\mathrm{x}}$ stretching at $2800-3100 \mathrm{~cm}^{-1}$. Note also the progressive disappearance of the high frequency $\mathrm{C}-\mathrm{H}_{\mathrm{x}} \mathrm{sp}^{2}$ modes $[12,15]$ with increasing $\mathrm{R}$. In particular, at $\mathrm{R}=80 \%$ there is 


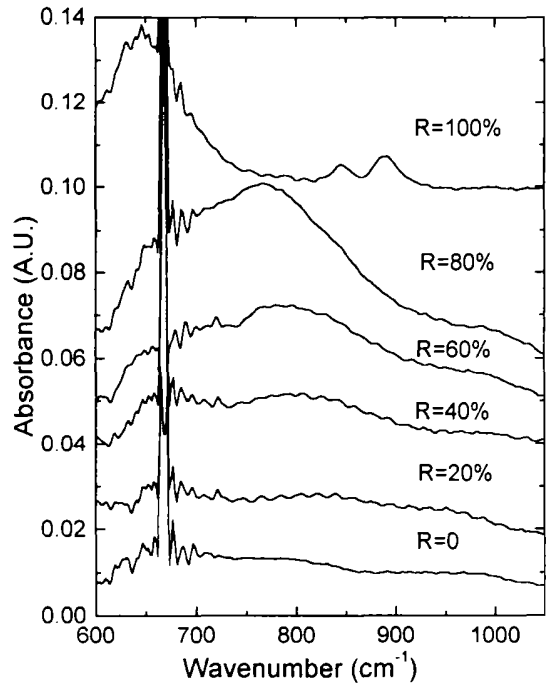

Fig 6: low frequency FTIR spectra of some samples with increasing $\mathrm{R}$

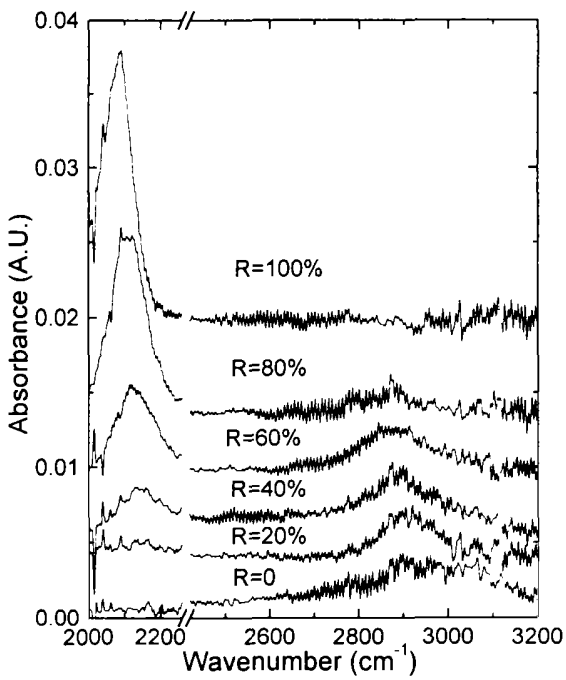

Fig 7: high frequency FTIR spectra of some samples with increasing $\mathrm{R}$

a maximum at $2870 \mathrm{~cm}^{-1}$ corresponding to $\mathrm{sp}^{3} \mathrm{CH}_{3}$ symmetrical stretching vibrations $[12,15]$, with a lower frequency shoulder due to $\mathrm{sp}^{3} \mathrm{CH}_{2}$ symmetrical stretching $[12,15]$. This again confirms that samples at $\mathrm{R}=80 \%$ have the highest $\mathrm{Si}-\mathrm{C}$ bonding, resulting in the highest $\mathrm{C} \mathrm{sp}^{3}$ fraction and optical gap. A similar trend in the $\mathrm{Si}-\mathrm{C}$ and $\mathrm{Si}-\mathrm{H}$ vibrations is seen in UV Raman data.

The Young's Modulus of an as-deposited ta-C:H is $\sim 300 \mathrm{GPa}$, as measured by Brillouin Scattering [8], with Poisson's Ratio of $\sim 0.3$. Nanoindentation was performed on thick $(>500 \mathrm{~nm})$ samples grown at $\mathrm{R}=20 \%$ and $40 \%$, resulting in hardness of at least $15 \mathrm{GPa}$ for $\mathrm{R}=40 \%$.

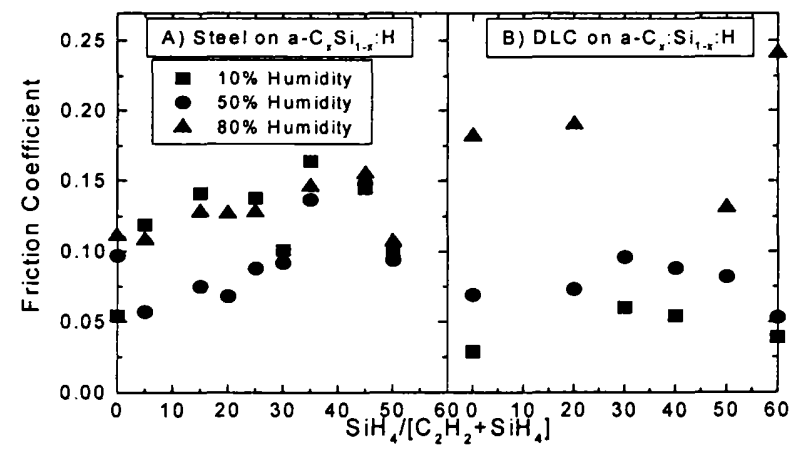

Fig 8 . Friction coefficient at $10,5080 \%$ humidity for a- $\mathrm{C}_{\mathrm{x}}: \mathrm{Si}_{1-\mathrm{x}}: \mathrm{H}$ films vs. $\mathrm{R}$ for $\mathrm{A}$ ) steel ball, B) diamond-like a-C:H coated steel ball

Friction tests were conducted for 2 hours. Fig 8 shows the steady friction coefficients. As-deposited ta-C:H, without $\mathrm{Si}$, shows excellent friction properties in the range $10-80 \%$ humidity ( $\mu=0.05-0.12$ ). This is comparable with $\mathrm{Si}$ incorporated a$\mathrm{C}: \mathrm{H}[2,3]$, whilst $\mu$ for a-C:H is known to increase with humidity up to 0.5 [9]. For 
$\mathrm{R}>50 \%$, with steel balls, and $\mathrm{R}>60 \%$, with DLC coated balls, film failure was observed with $\mu \sim 0.6$. Increasing $R$ gives a slight increase in $\mu$, but always less than $\sim 0.15$. Furthermore, high and low humidity result in roughly the same $\mu$, with a minimum at $50 \%$ humidity. Thus $\mathrm{Si}$ addition is useful to obtain low stress, low humidity sensitive films. Sliding against a DLC coated ball gives a very low $\mu$ at $10 \%$ humidity $(\sim 0.02-0.05)$. However, in this case, there is a sensible increase in $\mu$ with humidity, due to the deterioration of the friction properties of a-C:H coating the ball.

\section{CONCLUSIONS}

We have demonstrated that the ECWR source can be used for high rate deposition of a- $\mathrm{C}_{\mathrm{x}}: \mathrm{Si}_{1-\mathrm{x}}: \mathrm{H}$ alloys, ranging from ta-C:H to a-Si:H. We have analysed the structural and optical properties of these alloys. Ta-C:H shows a low, almost humidity insensitive friction coefficient of $\sim 0.05-0.1$. $\mathrm{Si}$ introduction $(\sim 10 \%$ $\mathrm{Si} /[\mathrm{C}+\mathrm{Si}])$ allows a $\sim 45 \%$ reduction of the stress, whilst maintaining low friction and low humidity sensitivity. Coatings with high hardness, low stress, low friction, and an optical gap of $2.5 \mathrm{eV}$ can thus be deposited, satisfying the requirements for a wide range of possible applications.

\section{ACKNOWLEDGEMENTS}

The authors would like to thank prof. D. Batchelder and Dr. D. Richards for Raman facilities, R. A. P. Smith and N. L. Rupesinghe for XPS data, S.E. Rodil and V. Stolojan for EELS measurements, UK EPSRC for financial support. A.C.F. acknowledges funding by an E. U. TMR Marie Curie research fellowship.

\section{REFERENCES}

1. J. Robertson, Phil. Mag. B, 66, 615 (1992)

2. K. Oguri and T. Arai, J. Mater. Res. 5, 2567 (1990)

3. K. Oguri and T. Arai, Thin Solid Films, 208158 (1992)

4. C. Donnet, Surf. Coat. Tech., 100-101 180 (1998)

5. M. Weiler et al. Phys. Rev. B, 531592 (1996)

6. N. A. Morrison, S. Muhl, S. E. Rodil, A. C. Ferrari, M. Nesladek, W. I. Milne and J. Robertson, Phys. Stat. Sol. A, 17279 (1999)

7. A. Libassi, A. C. Ferrari, V. Stolojan, B. K. Tanner, J. Robertson and L.M. Brown, Diam. Relat. Mater, to be published (1999).

8. A. C. Ferrari, J. Robertson, M. G. Beghi, C. E. Bottani, R. Ferulano and R. Pastorelli, Appl. Phys. Lett., 751893 (1999)

9. K. Enke, H. Dimigen and H. Hubsh, Appl. Phys. Lett., 36291 (1980)

10. A. A. Voevodin and M. S. Donley, Surf. Coat. Technol. 76, 534 (1995); Diam. Relat. Mater, 51264 (1996)

11. A. K. Gangopadhyay, P. A. Willermet, M. A. Tamor and W. C. Vassel, Trib. Intern., 309 (1997)

12. J. P. Conde et al.,J. Appl. Phys., 853327 (1999)

13. A. C. Ferrari and J. Robertson, Phys. Rev. B, submitted; these proceedings.

14. X. Zhang, W. H. Weber, W. C. Vassel, T. J. Potter and M. A. Tamor, J. Appl. Phys., 832820 (1998)

15. J. Ristein, R, T. Stief, L. Ley and W. Beyer, J. Appl. Phys, 843836 (1998) 